\title{
DESIGNING OF A LEARNING ENVIRONMENT FOR TEACHING OF DECISION-MAKING PROCESSES
}

\author{
Javier Albadán-Romero ${ }^{1 *}$, Paulo Alonso Gaona-García ${ }^{2}$ \\ ${ }^{1}$ M.Sc. in Information and Communications, Universidad Distrital Francisco José de Caldas, \\ Bogotá, Colombia, jalbadanr@correo.udistrital.edu.co \\ ${ }^{2}$ Dr. Engineering, Universidad Distrital Francisco José de Caldas, Bogotá, Colombia, \\ pagaonag@udistrital.edu.co \\ ${ }^{*}$ Corresponding Author
}

\begin{abstract}
This paper aims to present an e-learning environment initiative to train students in decision-making processes. The project consists in a learning environment based in gamification where a student can play in some situations while the psychological profile description is generated in background. The learning environment allows assessing student in the decision-making processes through some psychological competences related with the decision-making. These competences are: a) conviction ability, selfconfidence; b) orientation to be a methodical and planner person; c) the ability to keep a dynamism and concentration level; d) the self-control in some eventualities; e) the characteristics that shows a persevering person, who insists in the consecution of goals; and f) the features of integrity, while exists coherence between the actions with that proposes. The environment proposes some tips to enhance the psychological skills. These final game statistics deploy several characteristics, graphics and possible actions to improve psychological skills. In the validation process, the product obtained as a web application for managing a learning environment in decision-making skills for students, the application obtained subjective impressions of all participants and demonstrated the potential value of the approach to learning of decisionmaking. The purpose of this evaluation was to get values with which to analyze the feedback about decisionmaking and other basics skills to improve. The gamification of the teaching processes allows adding attractive features to motivate the student to engage with academic issues. In complement to this situation, the use of game consolidates as go-between to characterize details of student difficulties, along with the possible improve actions.
\end{abstract}

Keywords: gamification, decision-making, e-learning, learning environment, psychological competences.

\section{INTRODUCTION}

The basic principles that are worked are the implementation of game mechanics, the continuous learning and collaboration in the working place according (Corrigan, Zon, Maij, McDonald, \& Mårtensson, 2015). These elements are fundamental role because learning and work converge in the organization management.

(Azadegan \& Riedel, 2012) propose a classification about how serious game can be applied in companies 
establishing 4 categories: business training, change management, viral diffusion and gamificación. About this, the training and learning based in games are gaining credibility and popularity for business training. In change management, the goal is not training students but rather help to transform them with the company. Viral diffusion, have as great goal the integration which it is carried out across social media principally. Finally, gamification, that focuses in design of game mechanics and techniques to solve some problems and engage people. (Vidani, Chittaro, \& Carchietti, 2010) commented about to serious games help in training since simulations with advantages as availability, security and possibly, lower costs unlike real world simulations. In the context of learning organizations, as a suitable scenario that can be improve in dynamics, this research aims to give in the design of a digital environment that allows get implicitly the behavioral data and user answers in different events. This idea, matches with the concept that mechanics game it allows the tacit transfer of certain types of information according to (Winn, 2009).

This paper presents in the section 2 the conceptual elements related with research. In section 3 , methodology features are described. Section 4 and 5, details the e-learning environment design, and preliminary results respectively. Finally, presents conclusions and future works.

\section{BACKGROUND}

Below, it is presents succinctly, the topics that support this research. In his order, it will discuss about gamification and decision-making processes and then link together notions in the e-learning context, from the use of game mechanics applied in scenarios involved in decision-making.

\subsection{Gamification}

Initially, the gamification concept can be analyzed from several perspectives and can be applied in many areas. (Burke, 2012) summarize the gamification as description of the general trend of using game mechanics in non-entertainment environments such as innovation, marketing, training, student performance, health and social change. It is relevant to this study the student performance features.

The implementation of several characteristics of game mechanics means that features of aesthetics, game thinking, levels, badges of victory, scoring system, markers and time constraints are designed to engage people, motivate actions, promote learning and solve problems as supports (Kapp, 2012). This position according with (Zichermann \& Cunningham, 2011) who synthesizes that gamification is the process of game thinking and game mechanics application to engage users and solve problems. However, as says (Kapp, 2012), the elements that configured and define gamification are nothing news. The gamification has as principal purpose to influence in the personal behavioral to get some business goals previously established and must be in the same way to the personal goals, to achieve a sustainable gamification as proposes (Werbach \& Hunter, 2012).

The game mechanics extrapolated in non-entertainment context allows to consolidate in only one activity the following elements that makes a player expose all skills as says in (Goasduff \& Pettey, 2011), this make sure the player feel able to achieve goals and engage them keeping commitment. The elements are: clear goals, game rules, convincing narrative and challenging but achievable activities.

\subsection{Decision-Making Processes}

(Wang, Patel, Patel, \& Ying, 2003) describe a reference model of the brain layers in which the decisionmaking appear as one of the 37 fundamental cognitive processes found in higher cognitive brain layer and that concentrates the option choice among a set of possibilities. Also, describe a higher cognitive function as an advanced vital brain function that develops and acquires with the support of meta-cognitive functions. In (Assis Rodrigues \& de Souza, 2011) are listed other brain functions present in higher layer as the recognition, imagination, understanding, learning, reasoning, deduction, induction, decision-making, problem solving, explanation, analysis, synthesis, planning and quantification. As most important characteristics of the higher cognitive functions is that they are based on goals, motivations and will, and they can be acquired, molded and controlled.

In practice, the decision-making processes are directly related with daily problem solving, which is a basic feature of human behavior, as illustrated in (Wang, Dong, \& Ruhe, 2004) where a features of the problem concept are detailed. In complement to the relationship between decision-making and problem solving, in (Albadán-Romero \& Gaona-García, 2015) are presented 3 major activities in person's capabilities and that influencing decision-making processes are consolidated, which are: i) alternative proposing; ii) information capture; and iii) personal relationships, that covering aspects such as communication processes, teamwork, work under pressure, persuasion, etc. 


\subsection{E-Learning}

In the literature the gamification have a great impact in the students training process. In (Williams, Kapralos, Hogue, Murphy, \& Weckman, 2014) authors presented a simulation for training of fire service, which it was intended to take advantage of interactive techniques, innovative and the attractive immersion provided by the serious games. (Corrigan et al., 2015) carried out a study for change management in the aviation system in European Union. This work developed a game in an important European airport to support the implementation of an airport collaborative decision-making (A-CDM). The main goal of this game was to ease the communication and collaboration while introduces the A-CDM supporting the cultural changes between some countries. The project evaluation proves that game mechanics can supports the collaborative learning processes and improve communication, transcendental features that are involved in much of work in A-CDM.

(Lagro et al., 2014) perform the serious game implementation in the training of medical students for decisionmaking in a geriatric complex. With this research, they improved in the self-perception of some competences in areas as patient preferences and costs of medical care for the decision-making in the geriatric.

Bruzzone et al. (2014) highlight the importance and potential of serious games for the identification, development and learning of soft skills. In the interaction with a game, soft skills correspond with the ability to perceive stage's details or in the identification of information elements missing. The soft skills are the communication, creativity, learning, team working, etc. Riedel and Hauge (2011) illustrate a classification of skills that are mediated by serious games, where it differs from what Bruzzone et al. (2014) exposed as not only being mediated soft skills but also hard skills. The study was conducted in the top 100 organizations from a list drawn up by a newspaper of great recognition in the United Kingdom. The hard skills are related with decision-making, abstract processes, technical activities, etc.

\section{METHODOLOGY}

The methodology proposed for this research is constituted by 4 phases as illustrated in Fig. 1. 1) Identify psychological competences that allow characterize the decision-making processes; 2) Design of avatars with a features that can be related with human cognitive and behavioral characteristics; 3) Design of learning environment covering gamification properties; and 4) Tests and establishment of preliminary results. There is a principal idea that consists in the avatar choice before play in the environment to contrast the characteristics that wishes get stand out with the avatar and the actions performed while playing. In essence, tests were carried out where students play in the environment, and from their choices and actions performed, the data are collected, processed to consolidate a descriptive report of the student, which includes textual profile, statistical graphs and improvement actions proposed by the difficulties described in the profile as a learning and feedback moment.

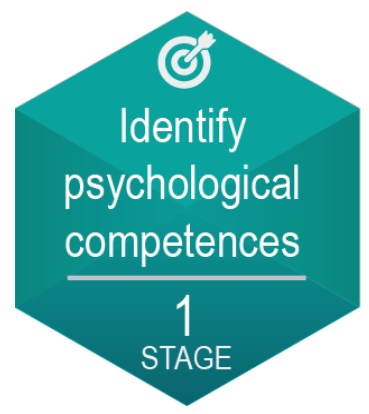

\section{MODEL DESIGN}

The model of learning environment developed is focused on the capture of several events such as percentages and types of actions performed, the order in which actions are carried out, the number of clicks, etc., which are generated in the student interaction with the game environment. With these events, the decision-making process is characterized and it is described through by six psychological competences, taken from (Alles, 2005):

\begin{tabular}{|l|l|l|l|l|l|}
\hline Dynamism & Planning & Integrity & Self-control & Conviction & Perseverance \\
\hline
\end{tabular}


The avatars, illustrated in Fig. 2, were designed since two organizational theories about leadership that classify the persons as eagles or ducks, worked in (Maxwell, 2015). In second part, (Conn \& Rieke, 1994), explain that the human behavior is characterized by five global dimensions:

\begin{tabular}{|c|c|c|c|c|}
\hline Anxiety & Independence & Toughness & Extraversion & Self-control \\
\hline
\end{tabular}

In the case of anxiety it was used the opposite property, Tranquility, for keep positive features. With this dimensions it was designed the five avatars, additional to eagle and duck, with aim that each avatar represent each global dimension respectively.
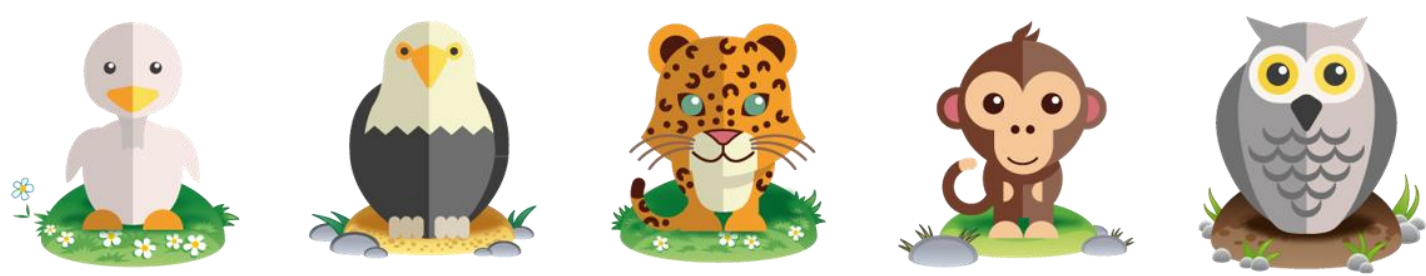

Fig. 2 Game avatars, in order: Duck, Eagle, Jaguar, Monkey and Owl. Source: System running.

The main goal in the game design is to extrapolate organizational or daily activities in challenges to the player, in this case the student. For this purpose, the conceptual base is the widely known pyramid of hierarchy of human needs established by (Maslow, 1943). For example in one scenario, the player must individually control each member of herd and go to food hunt. Such as one organization need primary resources, the food is the analogy because it is a basic need for animals. In one route, each member must capture and bring the food to the den while some events, arranged in manner unexpected and random between enemies and rivals appear. These events aim to challenge the player to capture the decisions taken along with other data. Before the player makes decision, the environment provides elements with some information to minimally support the player's decision.
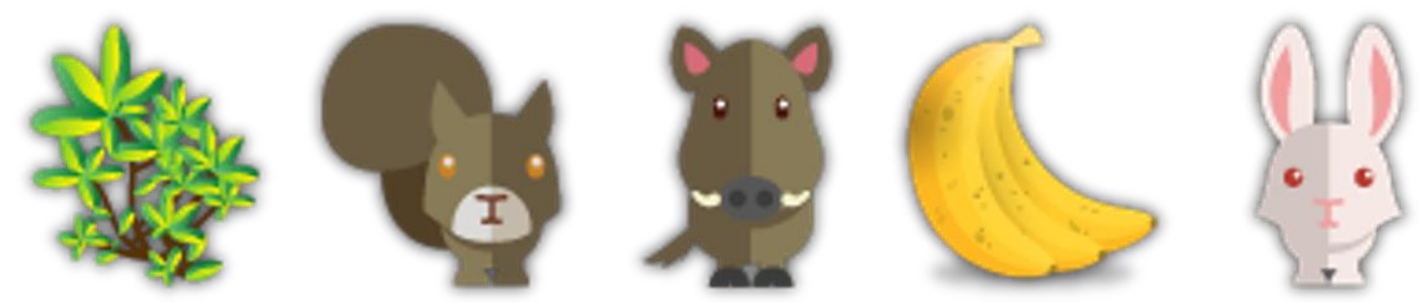

Fig. 3 Food of each avatar, in order: duck's food, eagle's food, jaguar's food, monkey's food and owl's food. Source: System running.

In technical terms, for the learning environment focused in the characterization of the decision-making processes, a Web application was designed with aim to taking advantage of their potential: cross-platform, no compatibility problems, does not occupy space in hard-drive of client (user/player). The interaction is based only in clicks and predominates event detection. It was worked with the generation of random elements in eventualities, scores and time constraints are also part of learning environment. The development of the learning environment ensures the latest standards of HTML5, CSS3, JavaScript, jQuery and implementation of different plugins that enhance the interaction and working under the premise of responsive design.

\section{PRELIMINARY RESULTS}

This section attempts to illustrate the product obtained as a web application for managing a learning environment in decision-making skills for students. The number of students who made the test were 45, all of them are professionals and some of them with master studies. The application was linked from Moodle as the LMS (learning management system) base with all topics about decision-making and leadership. However, the application developed does not integrate with LMS metrics. In an external questionnaire, it inquired to the students about the use and relevance of the game and it demonstrated a general perception of the potential value of the game approach in learning of decision-making processes. The purpose of this evaluation was to obtain values with which to analyze the feedback about decision-making and other basics 
skills to improve. Following, it is detailed the interaction and some results obtained in the proposed environment as seen in Fig. 4 and Fig. 5.

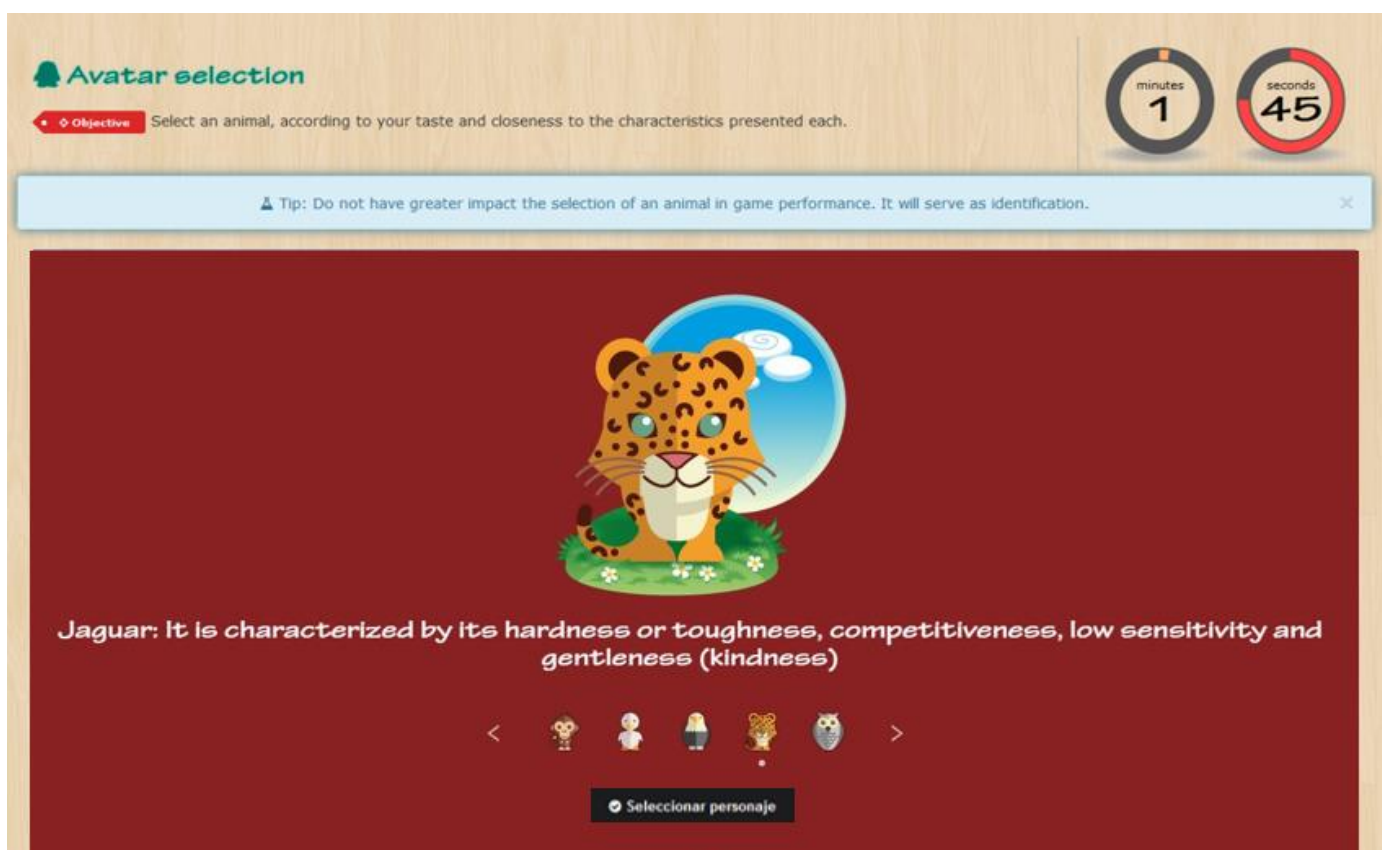

Fig. 4 Avatar selection. Source: System running.
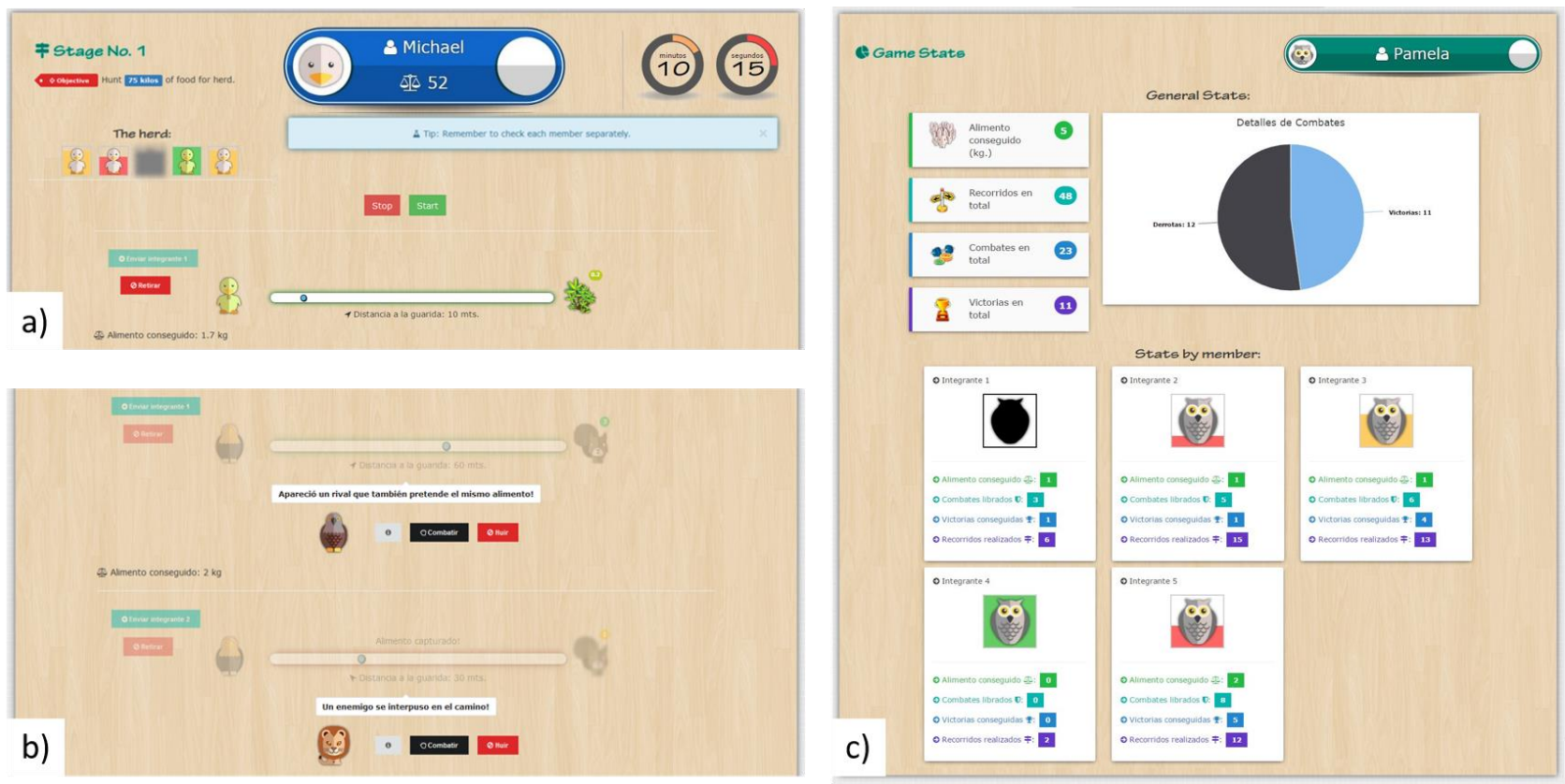

b)

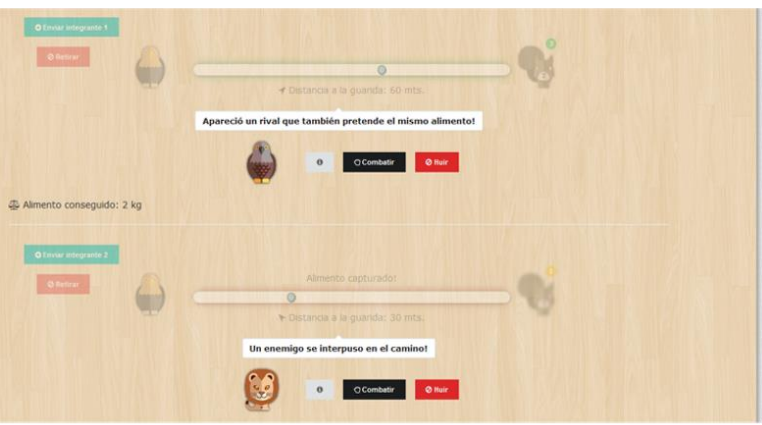

Fig. 5 a) Interaction in environment, food hunt by duck's herd. b) Random events creation, rival and enemy fights in eagle's herd. c) Final statistics of play, from the student role, with owl's herd. Source: System running

The preliminary results shows that only with the avatar choice it is possible to describe many characteristics of player and it can see a clear difference between a player who chooses the eagle or jaguar, where there is evidence that more than $75 \%$ of participants has a notable features of conviction, independence and planning, while more than $68 \%$ of participants that choose the duck or owl have features of self-control and tranquility in the time for decision-making. Overall, a third of the participants made choice of the eagle, another third jaguar, and the last third selected one of the other three animals.

Fig. $6 \mathrm{a}$ and Fig. $6 \mathrm{~b}$ illustrates the obtained report in self-evaluation about psychological competences carried out by an student/player, where it evidence the features that the player wants highlight them as the most 
developed in behavior. These metrics are generated with the initial interaction of the student, with the parameters.
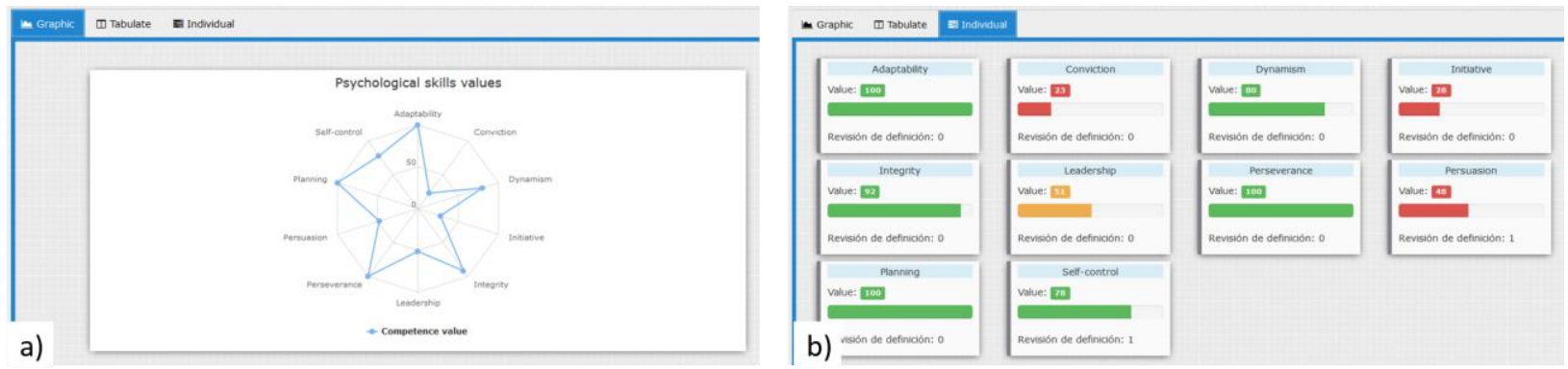

Fig. 6 Report of self-evaluation of psychological competences to support the profile player establishment: a) in graphic mode b) in individual detail. Source: System running

In the game interaction, a lot of data is captured to generate the player behavior. Fig. 7 allow to observe the metrics established to process the dynamism skill, in function to time. In this way, it can evidence if student keeps an increase, constant or descendent level of attention.

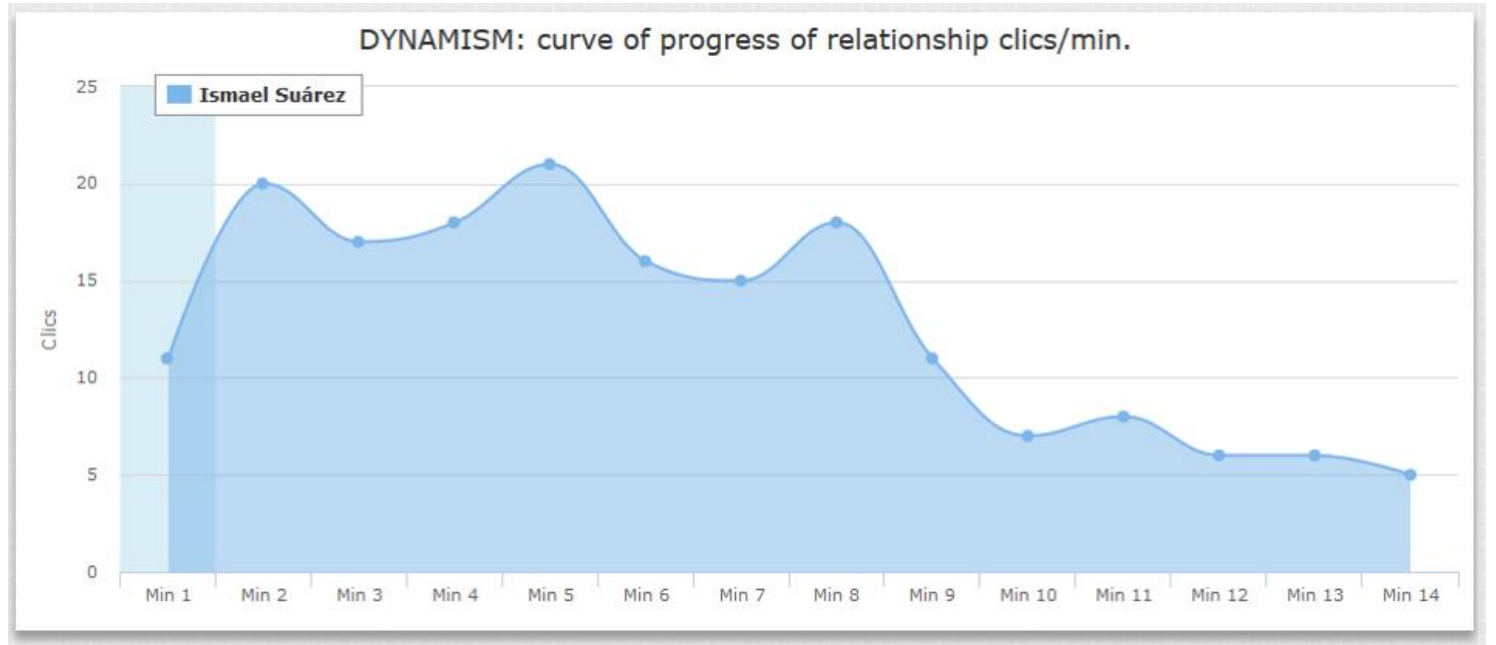

Fig. 7 Dynamism curve of an student. It evidences the decrease of performance.

It can observe inside the red circles, in Fig. 8a and Fig. 8b, a comparative between two different profile obtained of players (with different avatar) in planning terms. The report of each participant throws a curve with details of actions performed. With this information it is possible to identify a methodical person's profile, who executes sequentially actions and waits for conclusion of all task in course for begin again (on the left). And the other hand, the player that executes many actions, without a specific order, does not show as a methodical person, and solves many events at the same time depending on how they arise without waiting sequentially actions.
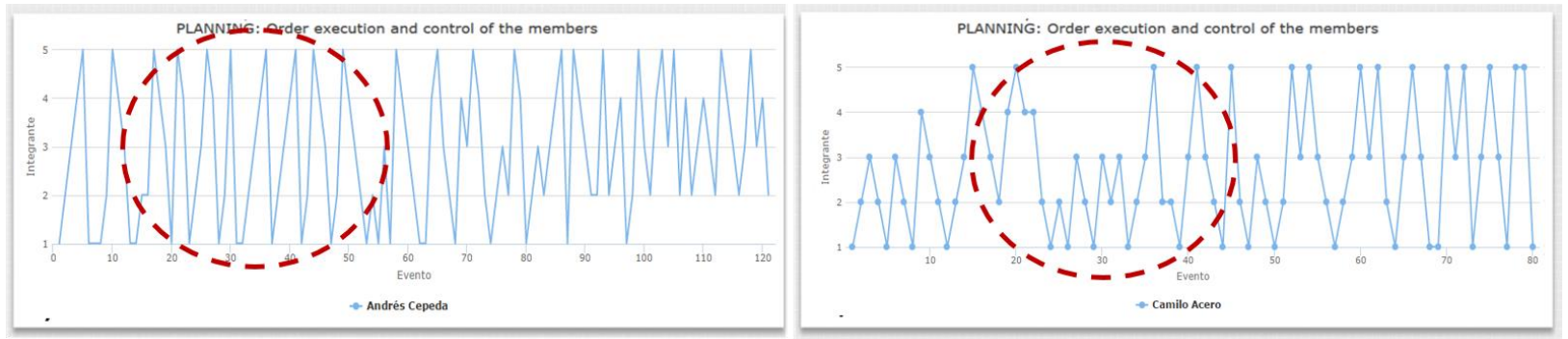

Fig. 8 a) Curve of planning consolidated by sequentially actions performed. b) Curve of an student that executes many actions at the same time. Source: System running

In complement for planning competence, it is also extracted the graphic given by the number of information requests to make a decision and the historical performance of one participant, this is shown in Fig. 9a and 
Fig. $9 \mathrm{~b}$ respectively, with eagle selection in this case. Finally, about conviction and integrity competences the report shows a similar graphic to Fig. 9a with percentages. In conviction competence are analyzed how many times that the student fights versus an enemy or rival. In integrity are analyzed the corresponding values between self-evaluation and the values obtained in each competence.

PLANNING: Requests for information before making a decision

Decisions with information requests

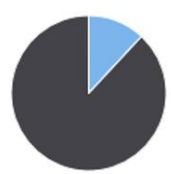

Decisions without request
PLANNING: History info request before a decision

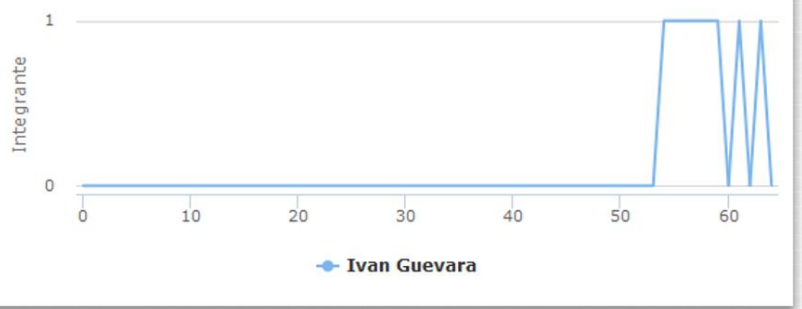

Fig. 9 a) Percentage of information requests as support to decision-making. b) Historical of information requests. Source: System running.

\section{CONCLUSIONS}

It is quite important to link organizational processes to learning environments, and, in this way the gamification of the organizational processes allow adding attractive features to motivate the student to engage with the company initiatives. In complement to this situation, the use of game consolidates as gobetween to characterize details of student difficulties along with the possible improves actions.

According to (Williams et al., 2014) is important clarify that game technologies have not capability of provide a real world scenario with all precision and a dynamic virtual environment with total fidelity. However, the design of this learning environment, as training tool for students, offers to a company: i) the simulation of an environment close to needs and profiles of company, ii) to identify features related with decision-making, and finally iii) to analyze students behaviors in uncertainty situations.

Based on our results, is important to mention that the decision-making processes were characterized in appropriately through psychological competences selected, which support and influences in the making decision of player. These competences are: a) conviction ability, self-confidence; b) orientation to be a methodical and planner person; c) the ability to keep a dynamism and concentration level; d) the selfcontrol in some eventualities; e) the characteristics that shows a persevering person, who insists in the achieving goals; and f) the features of integrity, while exists coherence between the actions with that proposes.

According to preliminary results, the six psychological competences selected could have a strong influence in decision-making. The student profile generated contains about 4 paragraphs of textual description with positive and negative features, and the possible actions to improve, which are taken from (Amason \& Schweiger, 1994) and (Jones, 2010) in the way that include organizational theories. When asked the 45 participants on average they believe that $82 \%$ of the information generated in profile is relevant. In addition, on average they consider that $76 \%$ of the statistics and graphics with interaction details are important and contributes significantly to know behavior characteristics and the possible improvements.

The animal choice, it was suitable considered to compare the actions performed in the learning environment and for extrapolate organizational activities. Initially, and according with organizational theories, the leaders must have tendency to behave and feel as eagles, so that the actions to improve are generated close to behavior of this animal, with features as dominance, the character to achieve goals, the low-level to be influenced, the effectiveness and efficient routing for its action.

As future work related, it is contemplated the implementation of other scenarios, equally based in basic organizational activities, that allow compare or complement the metrics here established, and another scenario that may include features of adaptive systems, that will change challenge and goals according of answers and actions of player. Additionally, it can propose other psychological competences that are important to students' capacitation with the same learning environment design. 


\section{REFERENCE LIST}

Albadán-Romero, J., \& Gaona-García, P. (2015). Modelo de actividades para la caracterización de procesos de toma de decisiones no programadas enmarcadas en escenarios de negociación. Research in Computing Science, Vol. 108, ISSN: 1870-4069, (pp. 1899-1106).

Alles, M. A. (2005). Gestión por competencias: el diccionario: Ediciones Granica SA.

Amason, A. C., \& Schweiger, D. M. (1994). Resolving the paradox of conflict, strategic decision making, and organizational performance. International Journal of Conflict Management, 5(3), 239-253.

Assis Rodrigues, S., \& de Souza, J. M. (2011). A Web Tool to Analyse Negotiation Behavior. Paper presented at the Multimedia and Ubiquitous Engineering (MUE), 2011 5th FTRA International Conference on.

Azadegan, A., \& Riedel, J. C. K. H. (2012). Serious Games Integration in Companies: A Research and Application Framework. Paper presented at the Advanced Learning Technologies (ICALT), 2012 IEEE 12th International Conference on.

Bruzzone, A. G., Massei, M., Tremori, A., Poggi, S., Nicoletti, L., \& Baisini, C. (2014). Simulation as enabling technologies for agile thinking: Training and education aids for decision makers. International Journal of Simulation and Process Modelling, 9(1-2), 113-127.

Burke, B. (2012). Gamification 2020: What Is the Future of Gamification? Gartner, Inc., Nov, 5.

Conn, S. R., \& Rieke, M. L. (1994). 16PF fifth edition technical manual: Institute for Personality \& Ability Testing, Incorporated.

Corrigan, S., Zon, G., Maij, A., McDonald, N., \& Mårtensson, L. (2015). An approach to collaborative learning and the serious game development. Cognition, Technology \& Work, 17(2), 269-278.

Goasduff, L., \& Pettey, C. (2011). Gartner says by 2015, more than 50 percent of organizations that manage innovation processes will gamify those processes: Gartner Press Release. Available at http://www.gartner.com/newsroom/id/1629214.

Jones, G. R. (2010). Organizational theory, design, and change (Fifth ed.): Pearson Upper Saddle River.

Kapp, K. M. (2012). The gamification of learning and instruction: game-based methods and strategies for training and education: John Wiley \& Sons.

Lagro, J., Van de Pol, M., Laan, A., Huijbregts-Verheyden, F., Fluit, L., \& Olde Rikkert, M. (2014). A Randomized Controlled Trial on Teaching Geriatric Medical Decision Making and Cost Consciousness With the Serious Game GeriatriX. Journal of the American Medical Directors Association.

Maslow, A. H. (1943). A theory of human motivation. Psychological review, 50(4), 370.

Maxwell, J. C. (2015). El manual de liderazgo: 26 lecciones fundamentales que todo líder necesita: Thomas Nelson Inc.

Riedel, J. C. K. H., \& Hauge, J. B. (2011, 20-22 June 2011). State of the art of serious games for business and industry. Paper presented at the Concurrent Enterprising (ICE), 2011 17th International Conference on.

Vidani, A. C., Chittaro, L., \& Carchietti, E. (2010, 25-26 March 2010). Assessing Nurses' Acceptance of a Serious Game for Emergency Medical Services. Paper presented at the Games and Virtual Worlds for Serious Applications (VS-GAMES), 2010 Second International Conference on.

Wang, Y., Dong, L., \& Ruhe, G. (2004, 16-17 Aug. 2004). Formal description of the cognitive process of decision making. Paper presented at the Cognitive Informatics, 2004. Proceedings of the Third IEEE International Conference on.

Wang, Y., Patel, S., Patel, D., \& Ying, W. (2003, 18-20 Aug. 2003). A layered reference model of the brain. Paper presented at the Cognitive Informatics, 2003. Proceedings. The Second IEEE International Conference on.

Werbach, K., \& Hunter, D. (2012). For the Win: How Game Thinking Can Revolutionize Your Business: Wharton Digital Press.

Williams, F. M., Kapralos, B., Hogue, A., Murphy, B. M., \& Weckman, E. J. (2014). Using Serious Games 
and Virtual Simulation for Training in the Fire Service: A Review. Fire Technology.

Winn, B. M. (2009). The Design, Play, and Experience Framework. In E. F. Richard (Ed.), Handbook of Research on Effective Electronic Gaming in Education (pp. 1010-1024). Hershey, USA: IGI Global.

Zichermann, G., \& Cunningham, C. (2011). Gamification by design: Implementing game mechanics in web and mobile apps: " O'Reilly Media, Inc.". 